\title{
Microplastics distribution in the Eurasian Arctic is affected by Atlantic waters and Siberian rivers
}

Evgeniy Yakushev (10) 1,2凶] Anna Gebruk (1) 3,4凶, Alexander Osadchiev (1) 2,5, Svetlana Pakhomova ${ }^{1,2}$, Amy Lusher (10 1, Anfisa Berezina (10 ${ }^{6}$, Bert van Bavel ${ }^{1}$, Elena Vorozheikina (1) ${ }^{7}$, Denis Chernykh ${ }^{8}$, Glafira Kolbasova9 ${ }^{9}$, llia Razgon ${ }^{9}$ \& Igor Semiletov 8,10

Plastic pollution is globally recognised as a threat to marine ecosystems, habitats, and wildlife, and it has now reached remote locations such as the Arctic Ocean. Nevertheless, the distribution of microplastics in the Eurasian Arctic is particularly underreported. Here we present analyses of 60 subsurface pump water samples and 48 surface neuston net samples from the Eurasian Arctic with the goal to quantify and classify microplastics in relation to oceanographic conditions. In our study area, we found on average 0.004 items of microplastics per $\mathrm{m}^{3}$ in the surface samples, and 0.8 items per $\mathrm{m}^{3}$ in the subsurface samples. Microplastic characteristics differ significantly between Atlantic surface water, Polar surface water and discharge plumes of the Great Siberian Rivers, allowing identification of two sources of microplastic pollution ( $p<0.05$ for surface area, morphology, and polymer types). The highest weight concentration of microplastics was observed within surface waters of Atlantic origin. Siberian river discharge was identified as the second largest source. We conclude that these water masses govern the distribution of microplastics in the Eurasian Arctic. The microplastics properties (i.e. abundance, polymer type, size, weight concentrations) can be used for identification of the water masses.

\footnotetext{
${ }^{1}$ Norwegian Institute for Water Research, Oslo, Norway. ${ }^{2}$ Shirshov Institute of Oceanology, Russian Academy of Sciences, Moscow, Russia. ${ }^{3}$ University of Edinburgh, School of GeoSciences, Edinburgh, UK. ${ }^{4}$ Lomonosov Moscow State University Marine Research Center, Moscow, Russia. ${ }^{5}$ Moscow Institute of Physics and Technology, Dolgoprudny, Russia. ${ }^{6}$ St. Petersburg State University, Saint Petersburg, Russia. ${ }^{7}$ Tomsk Polytechnic University, Tomsk, Russia. ${ }^{8}$ V.I. Il'ichev Pacific Oceanological Institute, Far Eastern Branch, Russian Academy of Sciences, Vladivostok, Russia. ${ }^{9}$ Pertsov White Sea Biological Station, Lomonosov Moscow State University, Moscow, Russia. ${ }^{10}$ Institute of Ecology, High School of Economics, Moscow, Russia. ${ }^{凶}$ email: evgeniy.yakushev@niva.no; anna.gebruk@ed.ac.uk
} 
$\mathrm{P}$ lastic pollution is globally recognised as a threat to marine ecosystems, habitats and wildlife $e^{1-3}$. One aspect of the plastic problem are microplastics that are most commonly defined as small plastic particles $1 \mu \mathrm{m}-5 \mathrm{~mm}$ in size ${ }^{4}$. Microplastics are of particular environmental concern because they are bioavailable to a wide range of marine organisms and are present in food webs ${ }^{5-8}$. The Arctic Ocean was considered free of plastic pollution until recently, but in the last years the number of publications reporting microplastics in the Arctic waters, sea ice, sediments and biota have been increasing ${ }^{9-24}$. Despite the growing evidence of plastics in the Arctic, there are still several knowledge gaps related to the sources, drivers, pathways and interactions with biota ${ }^{25}$, with some areas of the Arctic Ocean being particularly underreported in literature, such as the Eurasian Arctic - including the Kara, Laptev and East-Siberian Seas.

Long-range transport driven by the global Thermohaline circulation $^{12}$, together with input from local sea-based and coastal sources constitute main pathways by which plastic debris reaches the Arctic Ocean ${ }^{21,25}$. Further, the transport of microplastics in Arctic sea ice and its subsequent release during summertime ice melting may be another important potential source of plastic litter to the Eurasian Arctic surface waters. This is predicted to grow as the sea ice retreat progresses ${ }^{14,26}$.

Rivers have been posited as a considerable vector of plastic runoff to the marine environment ${ }^{27,28}$. The Arctic Ocean receives $11 \%$ of the global freshwater discharge with main contribution from the $\mathrm{Ob}$ $\left(510 \mathrm{~km}^{3}\right)$, Yenisei $\left(630 \mathrm{~km}^{3}\right)$ and Lena $\left(530 \mathrm{~km}^{3}\right)$ rivers ${ }^{29-31}$. Discharges of these rivers form freshened surface layers over wide areas of the continental shelf in the Kara, Laptev and East-Siberian Seas (Fig. 1) $)^{32,33}$. The Barents Sea, however, receives relatively low riverine discharge $\left(200 \mathrm{~km}^{3}\right.$ annually) and its surface waters are occupied by warm and saline Atlantic water inflowing from the North Atlantic 34,35 . To the extent of our knowledge there are no published data on the delivery and fate of river-borne plastic pollution to the Arctic Ocean. Identification of physical mechanisms that govern distribution of microplastics in the Arctic Ocean will provide valuable insights into global patterns of microplastics distribution, as well as contribute towards monitoring of microplastics concentrations and the success of the mitigation measures.

To address this knowledge gap, we analysed the distribution of microplastics in the surface and subsurface layers through in situ measurements in the Eurasian Arctic spanning from the Barents Sea to the East-Siberian Sea. The obtained data were compared to the presence of the principal Arctic surface water masses: (i) the Atlantic surface water; (ii) the Polar surface water; and (iii) Great Siberian rivers plumes. The specific goals were to (i) evaluate the level of microplastic pollution in different water masses in the Eurasian Arctic; (ii) assess spatial distribution, abundance, weight, size, morphology and polymer types of the sampled microplastics; and (iii) identify potential sources of microplastic pollution of the Eurasian Arctic.

\section{Results}

Quality control. No microplastics were found in any field $(n=3)$ or procedural $(n=9)$ blanks corresponding to the subsurface samples. A total of six fibres were found in the field blanks, and one fibre in procedural blanks. All fibres detected in the blanks were cellulose, which indicates high confidence that microplastics were not introduced to the samples as a result of contamination during sampling and processing procedures. As no field or procedural blanks were performed for the surface samples it was not possible to account for procedural error in the field.

No statistical correlations between microplastics characteristics and conditional variables (wind speed; ship velocity) were found (Supplementary Table S1). From these results, we inferred that the revealed differences in microplastics characteristics were not connected to the changes in the sampling conditions. A possible relationship was found between microplastics size and water salinity, and microplastics size and temperature; the related determination coefficients were equal to 0.52 and 0.53 (Supplementary Table S1).

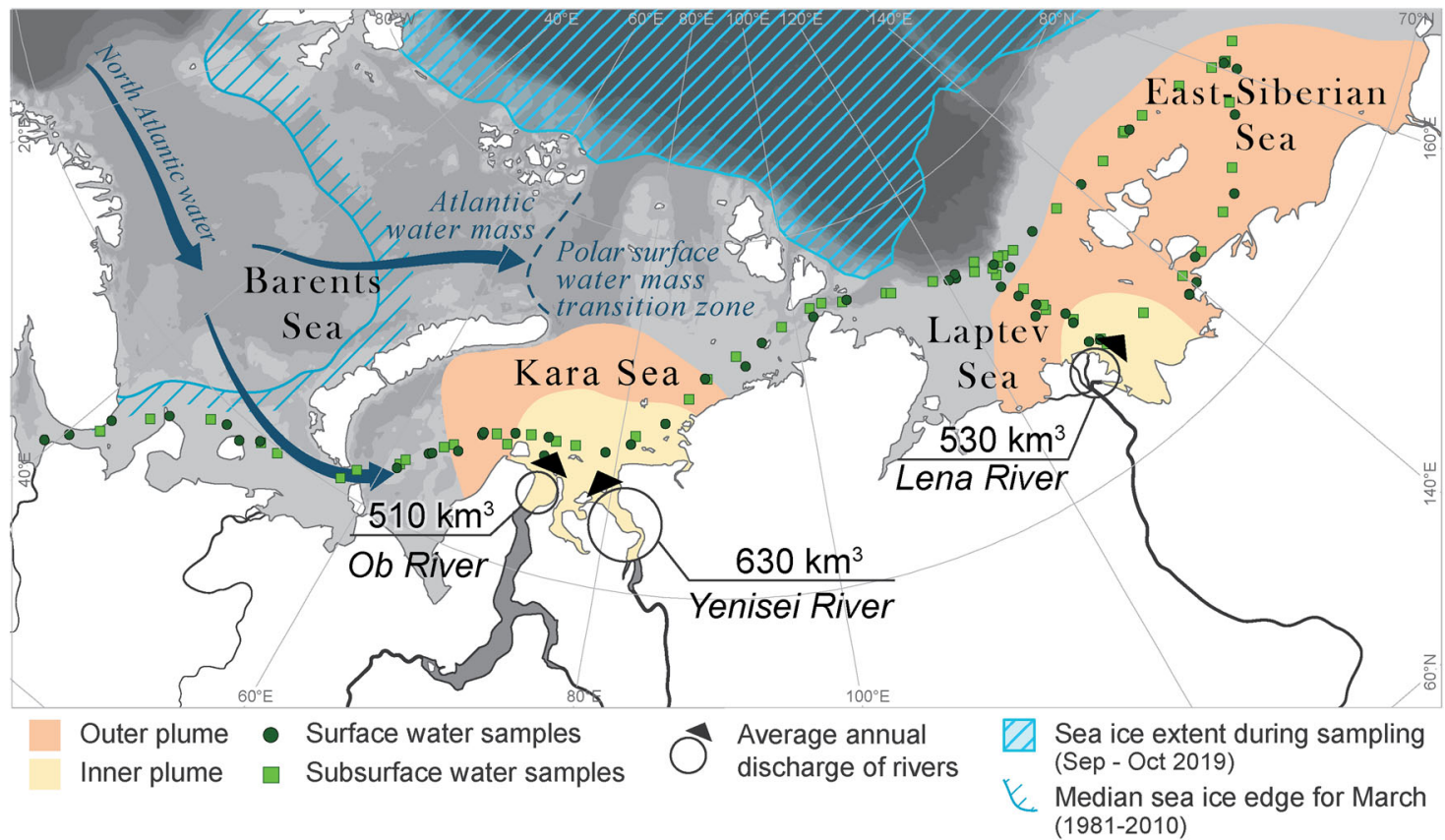

Fig. 1 Schematic map of bathymetry, main rivers, sea ice extent, average deposition of surface water masses in the study area and locations of surface (dark green circles) and subsurface (light green squares) water samples. The blue arrows indicate inflow of Atlantic surface water to the Eastern Arctic, the dashed blue line indicates the frontal zone between the Atlantic surface and Polar surface water masses. Sea ice extent was obtained through satellite data (data obtained from Terra, Aqua/MODIS, retrieved 03.03.2020). 

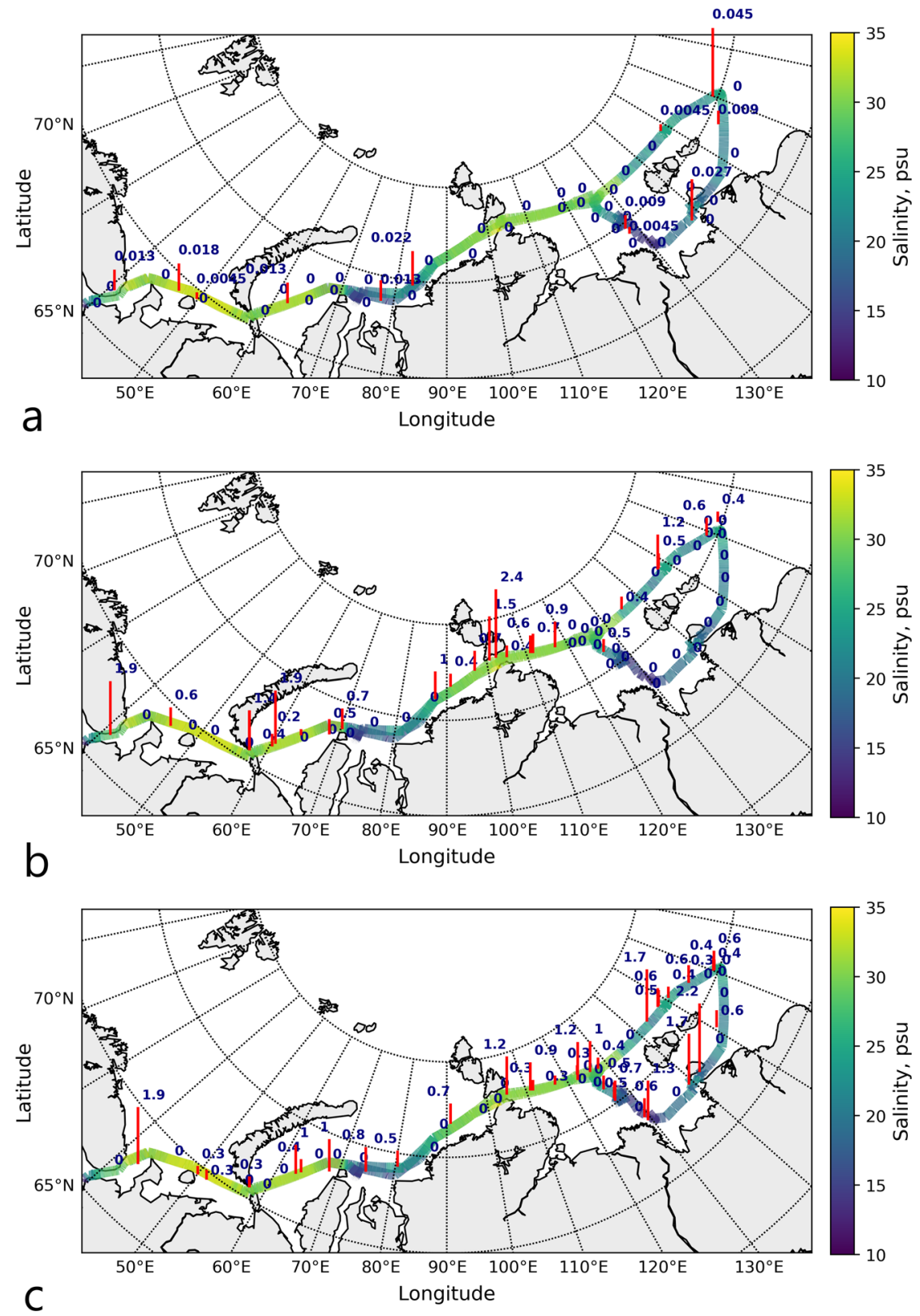

Fig. 2 Schematic map representing salinity gradient (multicoloured line) and abundance of microplastics (items $/ \mathrm{m}^{3}$ ) (red bars) along the ship track. a For the surface samples, $n=48$. b For the subsurface samples, fragments, $n=60$. c For the subsurface samples, fibres, $n=60$.

Microplastics in different water masses. Water sampling was performed in four different seas: the Barents, Kara, Laptev and EastSiberian seas. The borders of these seas do not correspond to borders of the water masses where circulation and interaction is presumed to govern transport of microplastics. During the studies within these four Seas, four different water masses were detected, namely, (i) the Atlantic surface water mass in the surface layers in the Barents and the western part of the Kara Sea ${ }^{36-38}$; (ii) the large freshened Ob-Yenisei plume that occupied surface layer in the central part of the Kara Sea ${ }^{39,40}$; (iii) the large freshened Lena plume in the surface layers in the eastern part of the Laptev Sea and in the western part of the East-Siberian Sea ${ }^{41,42}$; and (iv) the Polar surface water mass that occupied surface layer between the Ob-Yenisei and Lena plumes in the eastern part of the Kara Sea and in the western part of the Laptev Sea ${ }^{34,43}$. Due to similar characteristics, we did not distinguish the water masses of the Ob-Yenisei and Lena plumes (these can be colloquially referred to as Shelf water ${ }^{44}$ ). For the further analyses we have instead categorised them as low-saline inner (salinity of 0-16 psu) and more saline outer (16-28 psu) parts of these plumes. Spatial distribution of microplastics abundance in surface (Fig. 2a) and subsurface (Fig. 2b, c) water samples were plotted alongside water salinity.

Average abundance (calculated as items $/ \mathrm{m}^{3}$ and items $/ \mathrm{km}^{2}$ ) and average weight concentration $\left(\mu \mathrm{g} / \mathrm{m}^{3}\right)$ of detected microplastics in surface and subsurface water samples are shown in Table 1 for each sea and water mass studied. Data on microplastics abundance derived from previous research surveys in the Arctic and Atlantic Oceans provided in Table 1 for comparison. Generally, the obtained average for the Eurasian Arctic values are in the limits of the observed before and closer to the minimum values, i.e. 0.004 items $/ \mathrm{m}^{3}\left(800\right.$ items $\left./ \mathrm{km}^{2}\right)$ for the surface samples and 0.8 items $/ \mathrm{m}^{3}$ for subsurface samples. 


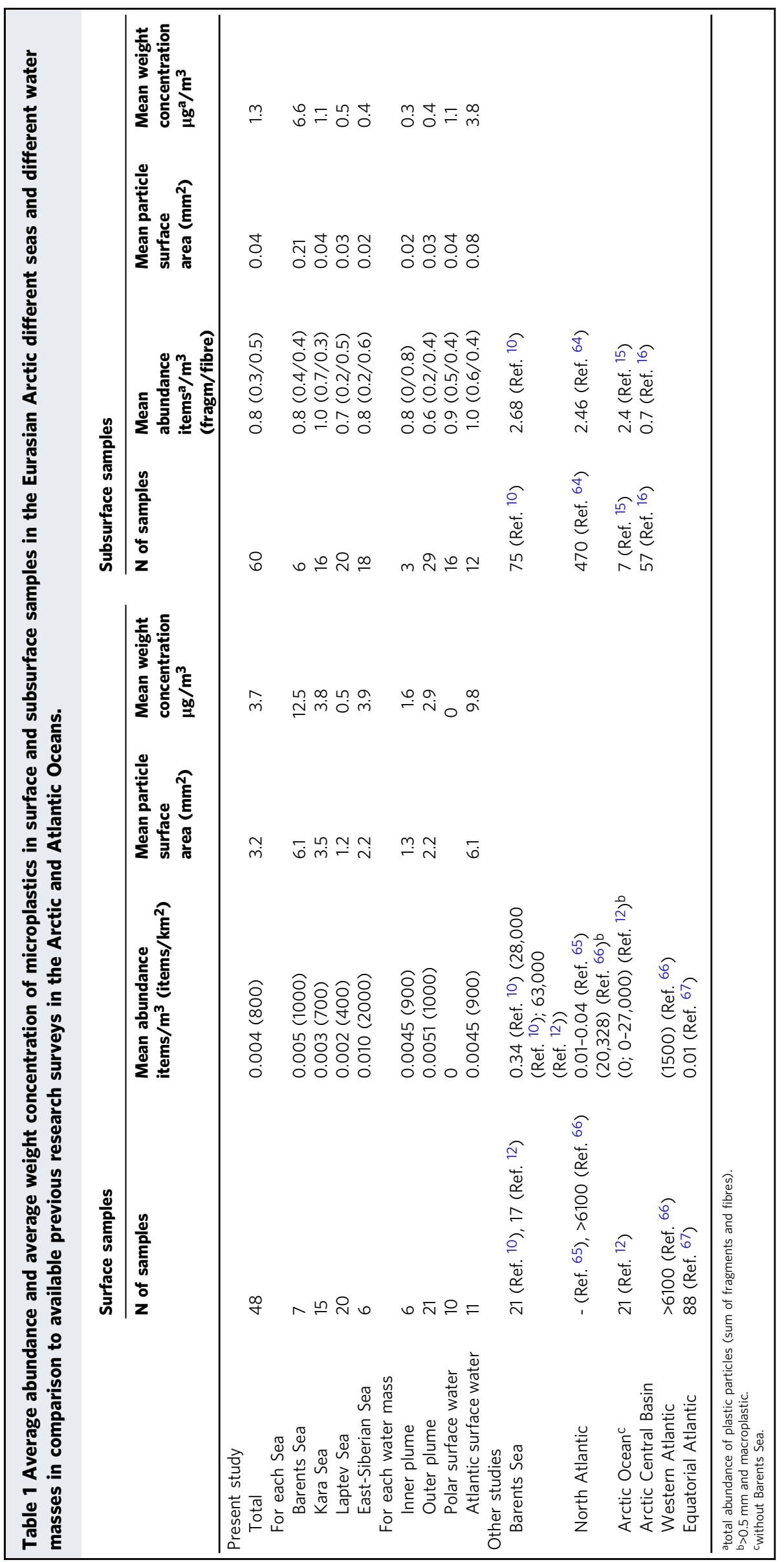




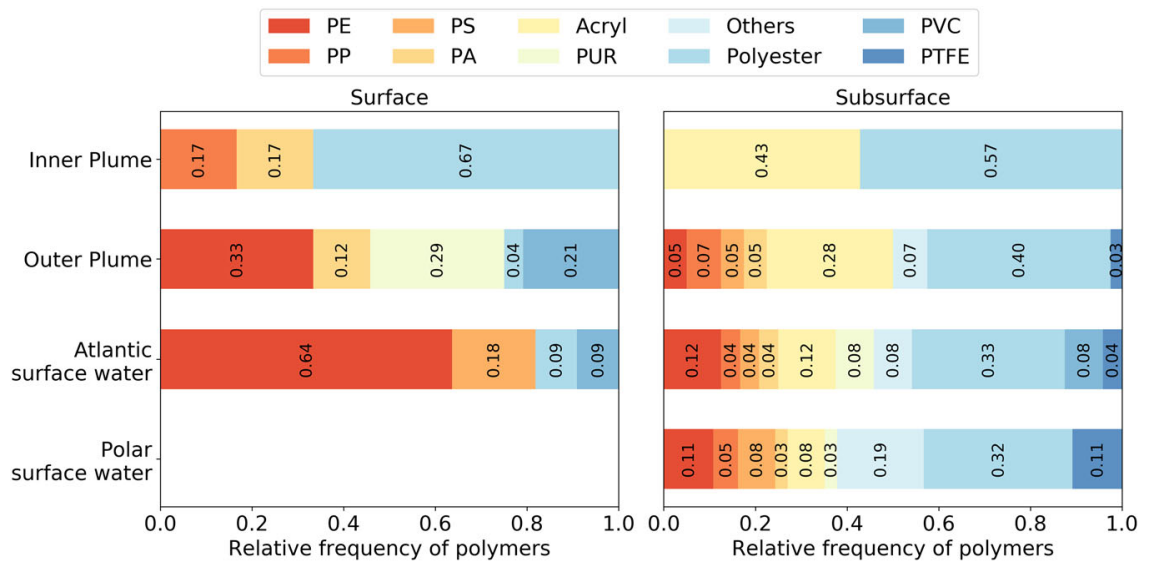

Fig. 3 Polymer types of microplastics normalised by number of stations within surface and subsurface samples for different water masses. Plastic types are listed from the lowest density to the highest density: polyethylene (PE), polypropylene (PP), polystyrene (PS), polyamide (PA), Acryl (fibres), polyurethane (PUR), others (nitrile butadiene rubber (NBR), styrene acrylonitrile resin (SAN), polyoxymethylene (POM), poly(2,6-diphenyl phenylene oxide) (PPPO), and phenoxy resin), Polyester (fibres), polyvinyl chloride (PVC) and Polytetrafluoroethylene (PTFE).

Surface water samples. A total of 258 particles were collected in surface water samples (Total filtered water volume: $10,670 \mathrm{~m}^{3}$ ), but only 41 of the particles were identified as plastics (15.9\%). Microplastics were found at 12 of 48 stations (25\%), ranging from 0 to 10 particles per sample. Three larger plastic fragments (10-30 mm long) were found in the Barents, Kara, and EastSiberian seas; they were identified as polypropylene (PP) but not considered in further analyses.

The abundance of floating microplastics varied from 0 to 0.045 items $/ \mathrm{m}^{3}\left(0-9000\right.$ items $\left./ \mathrm{km}^{2}\right)$, with an average of $0.004 \pm 0.009$ items $/ \mathrm{m}^{3}\left(800 \pm 2000\right.$ items $\left./ \mathrm{km}^{2}\right)$ calculated for the whole study area (Fig. 2 and Table 1). Among the studied seas, the Laptev Sea contained the lowest abundance of microplastics $\left(0.002\right.$ items $\left./ \mathrm{m}^{3}\right)$, whereas the East Siberian Sea contained the highest $\left(0.010\right.$ items $\left./ \mathrm{m}^{3}\right)$. Average size of microplastics for the whole research area was $2.5 \pm$ $1.5 \mathrm{~mm}$, varying from $0.2 \mathrm{~mm}$ in the Laptev Sea to $5.0 \mathrm{~mm}$ in the Barents Sea. The average surface area of the particles was $3.2 \pm 4.1$ $\mathrm{mm}^{2}$ ranging from $1.2 \pm 2.1 \mathrm{~mm}^{2}$ in the Laptev Sea to $6.1 \pm 6.6 \mathrm{~mm}^{2}$ in the Barents Sea. Average microplastics weight concentration was $3.7 \pm 11.5 \mu \mathrm{g} / \mathrm{m}^{3}$, (range $0-71 \mu \mathrm{g} / \mathrm{m}^{3}$ ). The highest weight concentrations of microplastics were observed in the Barents Sea $\left(12.5 \mu \mathrm{g} / \mathrm{m}^{3}\right)$, while in the other seas it was 1-2 orders of magnitude lower (0.4-1.1 $\left.\mu \mathrm{g} / \mathrm{m}^{3}\right)$. The majority of the microplastics were identified as polyethylene (PE) (36.6\%) followed by polyurethane (PUR) (17.1\%), polyvinyl chloride (PVC) (14.6\%), polyester (14.6\%), polyamide (PA) (9.8\%), polystyrene (PS) (4.9\%) and polypropylene (PP; 2.4\%; Fig. 3). Most microplastics were classified as fragments (80.5\%, including three films), the rest were fibres (19.5\%).

The influence of river plumes on the distribution of microplastics in the Kara, Laptev and East-Siberian seas $(n=$ 37 samples) was assessed (Table 1). Smaller microplastics (with surface area $<3 \mathrm{~mm}^{2}$ ) dominated in the low-saline inner plumes adjacent to the river estuaries and deltas, whilst in the outer plume microplastics had distinctly larger-sizes (with surface area up to $10 \mathrm{~mm}^{2}$; Fig. 4). There were negligible differences between average abundance of microplastics in the inner and outer plumes $\left(0.0045\right.$ items $/ \mathrm{m}^{3}$ and 0.0051 items $/ \mathrm{m}^{3}$ respectively), while a notable difference was detected for the microplastic weight concentration $\left(1.6 \mu \mathrm{g} / \mathrm{m}^{3}\right.$ and $2.9 \mu \mathrm{g} / \mathrm{m}^{3}$ respectively). The largest diversity in polymer types was found in the outer plume (five polymer types, $13 \%$ fibres) compared to the inner plume (three polymer types, 67\% fibres; Fig. 3). No microplastics were found outside of the river plumes, i.e., in the saline Polar surface water mass.
In comparison, there were similar abundances of microplastics in the Barents Sea and the Western Kara Sea Atlantic water $\left(0.0045\right.$ items $\left./ \mathrm{m}^{3}\right)$ as it was found in the river plumes. However, surface area, weight concentration, morphology, and polymer types were different in the Atlantic Water and in the plumes (Table 1 and Figs. 3 and 4). Particle surface area was different in Atlantic surface water and outer plume in the surface samples according to Student's $t$ test $(p<0.05)$, Supplementary Table S3; fibre/fragment ratios were different in Atlantic surface water and inner plume in surface samples according to Fisher test $(p<0.05)$, Supplementary Table S6. From these results two main sources of microplastics to the Eurasian Arctic Ocean were identified: the transport from the North Atlantic by the Atlantic surface water and discharges from the Great Siberian Rivers. This is further supported by the absence of microplastics in samples collected in the Polar surface water mass which is not directly influenced by these two microplastics sources.

Subsurface water samples. The total volume of filtered water was $159 \mathrm{~m}^{3}$. Microplastics were found in $83.3 \%$ of the analysed subsurface samples (50 out of 60 samples). A total of 665 particles were isolated during visual identification and only 111 (16.7\%) were confirmed to be plastic by FT-IR, this corresponds to between 0 and 7 items per sample. Two polytetrafluoroethylene (PTFE) fragments $(6-9 \mathrm{~mm})$ and three polyester fibres $(7-20 \mathrm{~mm})$ found in the Kara, Laptev and East-Siberian seas were excluded from the microplastics analysis. Microplastics size ranged from 0.1 to $3.6 \mathrm{~mm}$, with an average of 0.7 $\pm 0.7 \mathrm{~mm}$. Microplastics surface area varied between 0.0001 and $0.7 \mathrm{~mm}^{2}, 0.04 \pm 0.09 \mathrm{~mm}^{2}$ on average.

Microplastics in the subsurface samples were composed of almost equal amounts of fibres (55\%) and fragments (45\%, including 9 films). Fourteen different polymer types were identified (Fig. 3). Polyester was the most common type (39\%) followed by acryl (18\%), PE (8.1\%), PP, PS, PTFE (5.4\% each), and PA (3.6\%), PUR (2.7\%), PVC (2\%). The other types, nitrile butadiene rubber (NBR), styrene acrylonitrile resin (SAN), polyoxymethylene (POM), poly(2,6-diphenyl phenylene oxide) (PPPO), and phenoxy resin accounted for $1-2 \%$ each.

Abundance of microplastics in subsurface samples varied from 0 to 2.4 items $/ \mathrm{m}^{3}$, with an average of $0.8 \pm 0.6$ items $/ \mathrm{m}^{3}$. Relatively small variability in microplastics abundance was observed between 
different seas ranging from 0.7 items $/ \mathrm{m}^{3}$ in the Laptev Sea to 1.0 items $/ \mathrm{m}^{3}$ in the Kara Sea. However, there were statistically significant differences in microplastics morphologies (fragments and fibres) within the seas (Supplementary Table S9). The Laptev and East-Siberian seas contained the highest abundance of fibres (0.5 items $/ \mathrm{m}^{3}$ and 0.6 items $/ \mathrm{m}^{3}$, respectively) and the lowest abundance of fragments $\left(0.2\right.$ items $/ \mathrm{m}^{3}$ in both the Seas). The highest abundance of fragments was reported in the Kara Sea $(0.7$ items $\left./ \mathrm{m}^{3}\right)$. Distinct differences were also observed in microplastics surface areas among the studied seas $(\mathrm{p}<0.05$, see Supplementary Table S7). The average surface area of microplastics in the Barents Sea $\left(0.2 \mathrm{~mm}^{2}\right)$ was an order of magnitude larger than in the other seas $\left(0.01-0.03 \mathrm{~mm}^{2}\right)$. There were also differences in microplastics weight concentration between the seas with a decreasing trend from the Barents Sea to the East-Siberian Sea (Table 1).

Analysis of microplastics distribution in different water masses showed a distinct increase in abundance of fragments, particle surface area, weight concentration, and number of polymer types from inner plumes to the outer plume, and to the open sea (Table 1 and Figs. 3-5). The inner plumes were characterised by the highest abundance of fibres and an absence of fragments (Table 1).

Microplastics characteristics in subsurface samples from the Atlantic surface water mass and in the riverine plumes were different: abundance of fragments was different in Atlantic surface water and outer plume according to Student's $t$ test $(p<0.05)$, Supplementary Table S3; fibre/fragment ratios were different in Atlantic surface water and both inner and outer plumes in subsurface samples according to Fisher test $(p<$ 0.05), Supplementary Table S6. As a result, subsurface microplastics transported to the Arctic Ocean from the North Atlantic can be statistically distinguished from those discharged from the $\mathrm{Ob}$, Yenisei and Lena rivers. These water masses have about the same abundance of microplastics (0.8-1.0 items $\left./ \mathrm{m}^{3}\right)$ while microplastics weight concentration differs by one order of magnitude $\left(3.8 \mu \mathrm{g} / \mathrm{m}^{3}\right.$ and $0.3 \mu \mathrm{g} / \mathrm{m}^{3}$ for the Atlantic surface water mass and river plumes, respectively; a
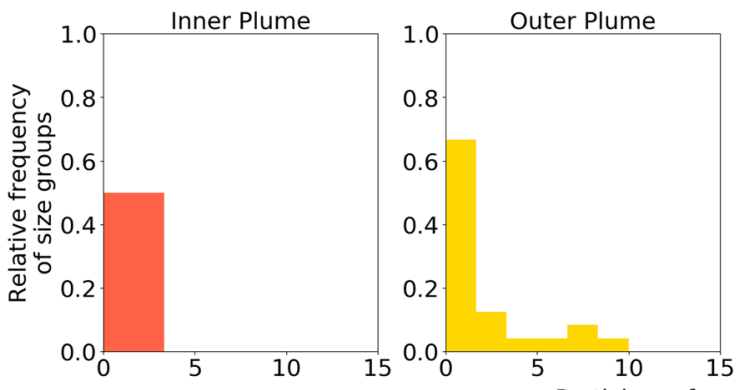

Particle surface area, $\mathrm{mm}^{2}$
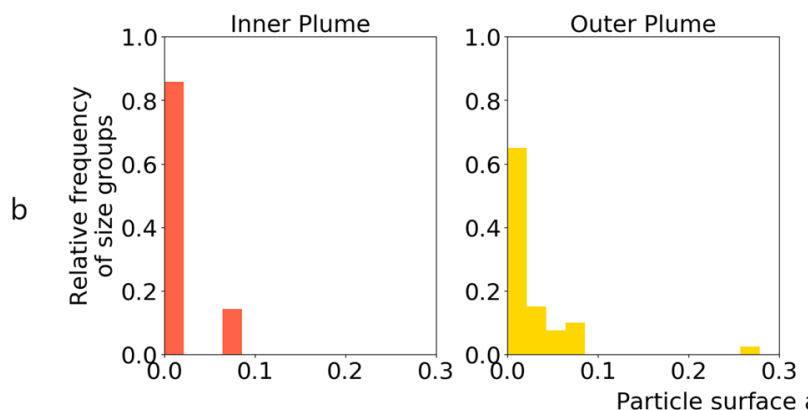
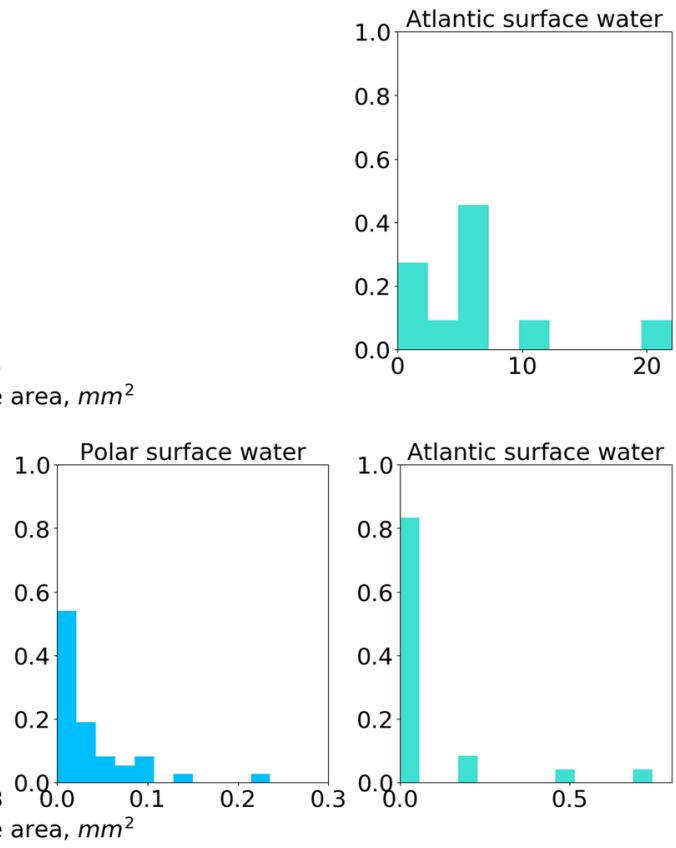

Fig. 4 Distributions of surface areas of microplastics normalised by number of stations within different water masses. a Surface samples, $\mathbf{b}$ subsurface samples. Red colour - inner plumes, yellow - outer plumes, blue - Polar surface water mass, green - Atlantic water mass.
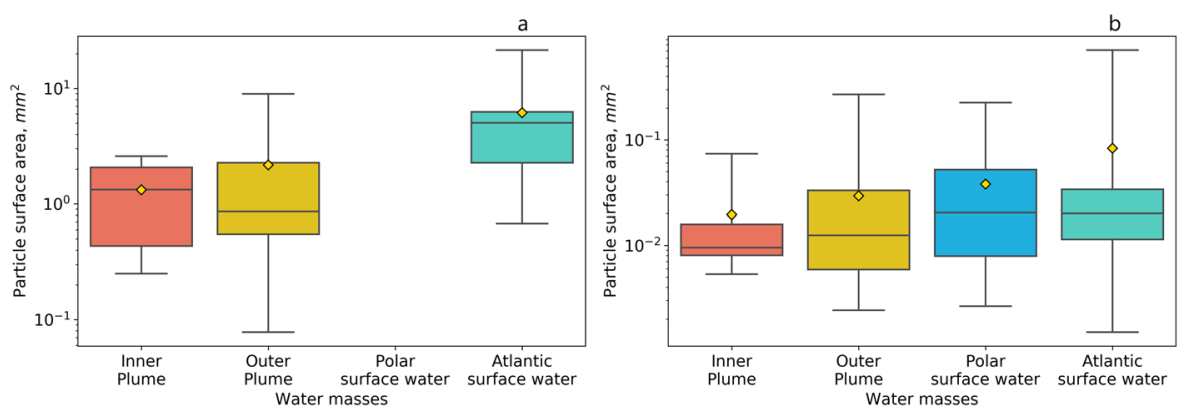

Fig. 5 Distribution of surface areas of microplastics for different water masses for surface. a surface samples, b subsurface samples. Red colour - inner plumes, yellow - outer plumes, blue - Polar surface water mass, green - Atlantic water mass. The coloured boxes represent interquartile range (25th to the 75th percentile), while the whiskers show the range of surface area within the water mass, horizontal lines in the boxes and yellow diamonds show the median and mean values respectively. 
Table 1). Subsurface microplastics in the Polar surface water mass had similar morphology, polymer types and abundance of items to those found in the Atlantic surface water mass (Table 1 and Figs. 3 and 5).

\section{Discussion}

Despite the overall growing scientific evidence of presence of microplastics in the Arctic Ocean (reviewed in $11,24,25$ ), our understanding of pathways and distribution of microplastics is still limited and paucity of data coverage prevents researchers from mapping and estimating relative importance of different sources of plastic pollution in the region ${ }^{21}$. Specifically, delivery of microplastics into the Eurasian Arctic from the Great Siberian Rivers was not previously considered in any numerical models due to absence of in-situ measurements of microplastics concentrations in these rivers. In this context our field measurements and results provide new important insights into distribution and potential sources of microplastics in the Eurasian Arctic Ocean. In the present study a systematic assessment of the distribution and characteristics (size, surface area, polymer type and weight) of microplastics was conducted in the surface and subsurface layers of the Eurasian Arctic Ocean (48 surface neuston net samples and 60 subsurface pump samples).

The measured abundance and weight concentration of microplastics revealed relatively low but consistent presence of microplastics in all four studied seas (the Barents, Kara, Laptev and East-Siberian seas), this is in agreement with other published literature (Table 1).

Analysis of spatial distribution of microplastics abundance in the Eurasian Arctic together with analysis of the different microplastics characteristics let us to identify two different sources of microplastics, namely, inflow from the North Atlantic and discharges from the Great Siberian Rivers. This is supported by earlier studies suggesting that the North Atlantic drift carries a large volume of marine plastic from the polluted Northern part of the Atlantic Ocean to the Barents Sea ${ }^{2}$. During transit through the Barents Sea, the Atlantic surface water mass is transformed due to winter convection and ice formation processes, specifically the water density increases ${ }^{43,45}$. As a result, the Atlantic water submerges below the Polar surface water mass in the northern part of the Barents $\mathrm{Sea}^{46}$ and its circulation will no longer influence transport of floating microplastics.

Floating microplastics advected from the North Atlantic are registered only in the western part of the study area and are composed mainly of polyethylene. The fate of microplastics is strongly influenced by seasonality in the Arctic due to dramatic change in sea surface conditions. Transport of microplastics in the sea surface layer during the warm season is dramatically modified once the cold season starts and solid ice cover is formed within the study region. Floating microplastics are trapped by sea ice during the ice formation in the northern part of the Barents Sea ${ }^{9,14}$ and then are transported eastward within the sea ice to the northern part of the Kara Sea and the Severnaya Zemlya archipelago ${ }^{47}$. However, the sampling campaign of the present study was conducted at the end of the warm season in September-October and did not intersect with the ice formation period, which started in the beginning of November. Therefore, the fate of microplastics during the cold season including its trapping during ice formation, its transport governed by ice circulation patterns, and its release to sea water during ice melting requires further targeted research.

On the other hand, river-borne floating microplastics are composed mainly of polyester fibres and appeared to accumulate within the buoyant plumes adjacent to estuaries and deltas of the $\mathrm{Ob}$, Yenisei and Lena rivers. The $\mathrm{Ob}$, Yenisei and Lena rivers inflow to the southern parts of the Kara and Laptev seas and carry riverine plastic collected from wide river watershed areas $(8$ million $\mathrm{km}^{2}$ in total, Fig. 1). Riverine microplastics distribution is strongly dependent on the spreading of the Ob-Yenisei and Lena plumes. The dynamics of these plumes depend on river discharge rate and wind forcing and, therefore, are prone to large seasonal and inter-annual variability $31,48-50$. Variability of position and area of the Ob-Yenisei and Lena plumes governs variability of stratification and circulation of the sea surface layer in the Kara, Laptev and East-Siberian seas. This directly affects the distribution of river-borne microplastics. The internal structure of these plumes can also affect the fate of marine microplastics due to their possible convergence and accumulation at multiple internal frontal zones formed within the plumes ${ }^{39,40}$. In situ sampling at several neighbouring sample sites within the plumes identified large microplastics spatial variability. The largest registered difference of the microplastics abundance was 0.045 items $/ \mathrm{m}^{3}$ at a distance of several $\mathrm{km}$ in the outer part of the Lena plume. However, more extensive sampling within the river plume is required to obtain a clearer statistical significance.

Microplastics with different morphologies have different spatial patterns in the subsurface samples. Subsurface microplastic fibres were found in all seas and all water masses; however, the largest abundance was observed within the river plumes. High abundance of fragments in the subsurface layer were only observed in saline water and were almost absent in river plumes, especially in their low-saline inner part. The same abundance of microplastics was found within the subsurface samples of the Atlantic surface water mass in the western part of the study region and within the Polar surface water mass between the Ob-Yenisei and Lena plumes. However, floating microplastics were absent in the Polar surface water which is not directly influenced by advection of water masses from the North Atlantic. A possible explanation for this observation is the transport of floating microplastics from the North Atlantic to the Barents Sea and the western part of the Kara Sea occurs during relatively short ice-free season from July to August to October ${ }^{51}$. Subsequently, floating microplastics are trapped by sea ice during the autumn and are transported eastward within ice towards the Vilkitsky Strait. Due to absence of floating microplastics in this area, accompanied by highest abundance of subsurface microplastic fragments, we presume that released microplastics do not remain at sea surface but sink to the subsurface layer after ice melting. This feature can be caused by physical and/or biological processes that modify floating properties of ice-trapped microplastics. It also explains the absence of subsurface fragments of microplastics in the river plumes. Floating microplastics in the plumes were discharged from the rivers to sea during ice-free period and were not trapped by sea ice. The mechanism of microplastic transport by the sea ice is discussed in Peeken et al. ${ }^{14}$ and later in Kanhai et al. ${ }^{22}$, however, we are not aware of any work that addresses transformation of floating properties of ice-trapped microplastics and this issue requires a specific study.

The lower abundance of microplastics observed in this study compared with other investigations (Table 1) may be associated with consideration in this study of particles $>100 \mu \mathrm{m}$ to be comparable to the previous research, as well as the sampling procedure which was adopted for subsurface samples to minimises procedural contamination. In addition, the use of an FT-IR analysis on all found particles further increased the accuracy of microplastics identification and decreased the final number of particles identified as plastics. This is in comparison to some of earlier studies that did not confirm the identity of all microplastics (i.e. refs. ${ }^{10,12}$ ). While our results are the same level as found for Arctic Central Basin ${ }^{16}$, where similar sampling and plastic identification procedures were used. This reinforces the importance of a harmonised suite of methodological approaches for microplastics analysis. The sampling procedure could be further optimised to investigate particles $<100 \mu \mathrm{m}$. 
The majority of previous plastic pollution studies were devoted to the plastic litter in the freshwater systems (reviewed in refs. ${ }^{52-54}$ ) and litter inputs from rivers to the marine environment ${ }^{55}$. However, less attention was paid to the studying of the fate of the riverine plastic litter after it was discharged and before it reached the open sea. Therefore, the present study provides baseline data on the role of the Great Siberian Rivers in the distribution and potential sources of microplastics in the Arctic Ocean. Our results suggest that these rivers provide the same abundance (number) of microplastics as the Atlantic waters, albeit river-borne microplastics are smaller in weight. Our results are in agreement with earlier hypothesis of Van Sebille and colleagues about a potential accumulation zone in the Barents Sea ${ }^{56}$ forming through the transport of microplastics from the North Atlantic. Our study found that the Atlantic surface waters were enriched with microplastics.

Generally, the analyses of both surface and subsurface data collected with independent methods gave similar results about difference of abundance and weight concentrations in the considered water masses. Therefore, we suppose that using both techniques together can be an advantage of the ocean microplastics studies as looking at different parts of the water column is important, one method misses what the other captures. But a comparison of sampling methods between trawling and water pumping is a separate task, (as discussed in ${ }^{4,10,57}$ ), that requires specific investigations, i.e. sampling from exactly the same volume of water with both techniques, that can be planned in the future studies. Although outside of the scope of this paper, atmospheric transport to the Eurasian Arctic is important for the small size microplastics $(<50 \mu \mathrm{m})^{11,18}$.

To conclude, the present study has shown that the marineborne microplastics (microplastics advected from the North Atlantic), and the river-borne microplastics (microplastics inflowed with discharge from the Great Siberian Rivers), have distinctly different physical (size, morphology, weight) and chemical (polymer type) characteristics. As a result, the marine-borne and river-borne microplastics can be statistically distinguished. The spatial distribution of these two types of microplastics is governed by spreading and transformation of the related water masses, the Atlantic water mass and the river plumes. Therefore, river discharge and distribution of buoyant riverine plumes needs to be considered together with global thermohaline circulation to better understand the delivery and fate of microplastics in the Arctic Ocean. We can also suggest that the microplastics properties (i.e. abundance, polymer type, size and weight concentrations) can be used for identification-of the water masses.

\section{Methods}

Terminology. The following terms are used throughout the text to characterise microplastic particles:

- "Microplastics"- Plastic particles which have all measurable dimensions shorter than $5 \mathrm{~mm}$ in size. The limit of detection in the case of this study is $>200 \mu \mathrm{m}$ for surface samples and $>100 \mu \mathrm{m}$ for subsurface samples.

- "Size" [mm] - the longest measurable dimension (Caliper length) of a particle irrespective to morphology (i.e. fragment or fibre).

- "Surface area" $\left[\mathrm{mm}^{2}\right]$ - an area of the largest measurable surface area of a particle irrespective to morphology.

- "Abundance of microplastics" [item $/ \mathrm{m}^{3}$ or item $\left./ \mathrm{km}^{2}\right]$ is a number of microplastics standardised to the volumetric or areal unit, i.e. $\mathrm{m}^{3}, \mathrm{~km}^{2}$.

- "Weight concentration of microplastics" $\left[\mu \mathrm{g} / \mathrm{m}^{3}\right]$ is a mass of microplastics standardised to the volumetric unit.

- "Morphology" - used to determine the shape characteristics of a particle, including fibres and fragments.

- "Polymer type" - the chemical makeup of a particular particle. This can be determined using chemical identification techniques such as FTIR instrumentation.

Study area. Floating plastic debris were sampled during the $78^{\text {th }}$ research cruise of the R/V Akademik Mstislav Keldysh in September-October 2019 in the Barents, Kara, Laptev and East-Siberian Seas (Fig. 1). Samples of floating particles were collected from surface water using a neuston net and from subsurface water using a ship-board underway pump-through system. A total of 60 subsurface water samples and 48 surface neuston samples were collected (Fig. 1). During net towing, the relevant vessel characteristics including speed and distance were recorded. The vessel heave, pitch and roll were not seen to affect earlier studies and therefore assumed negligible in this study. The towing was performed in calm weather conditions. Physical and chemical characteristics of surface water (temperature, salinity and dissolved oxygen), air (temperature, wind speed and atmospheric pressure) were continuously measured along the ship track.

Surface water sampling. The sampling protocol and the routine for classification were adopted from the most recent guidelines for microplastics sampling ${ }^{58}$. Surface water samples were collected using a neuston net with mesh size of $200 \mu \mathrm{m}$ and mouth opening of $40 \times 60 \mathrm{~cm}$. The net was deployed from the right side of the vessel and submerged at the depth of $20 \mathrm{~cm}$ in the sea. The net was towed along a straight line during $30 \mathrm{~min}$ per sample at a speed of $2 \mathrm{knots}^{59}$. Despite the fixed duration of the towing time intervals, towing distances varied by $\sim 5 \%$ due to occasional instabilities in vessel speed and impact of sea surface currents. The amount of filtered water was equal to $220 \pm 11 \mathrm{~m}^{3}$ according to the GPS track of the vessel, estimated as a difference in geographical positions of the beginning and the end of towing. The estimated variability of water volume for an individual towing was considered during the analysis of sampling results. After towing, the net was rinsed outside the vessel with a deck hose and returned to the ship deck. The codend was removed and taken to the vessel laboratory where it was rinsed, and volume reduced into a metal sieve with mesh size of $200 \mu \mathrm{m}$ using pre-filtered Milli-Q water. To minimise potential contamination from airborne fibres the samples were protected by a metal lid when possible. The collected particles $(0.2-5$ $\mathrm{mm}$ ) were stored in hermetically closed glass petri dishes pre-rinsed using prefiltered $(0.45 \mu \mathrm{m})$ Milli-Q water until the analysis in the onshore laboratory.

Subsurface water sampling. Subsurface seawater was collected by a ship-board underway pump-through system with an intake located at a depth of $3 \mathrm{~m}$ on the right side of the vessel. The water flow within the pump-through system was provided by a 900 -watt onboard pump $(\text { Metabo })^{60}$. The system was equipped by a thermosalinograph (SBE 21 SeaCAT) that was continuously recording salinity and temperature of flowing subsurface seawater. In order to perform microplastic sampling, flowing subsurface seawater was passed under pressure through two stainless steel meshes $(1.5 \mathrm{~mm}$ and $100 \mu \mathrm{m}$ pore size) within the filtration system, which consisted of two sequentially established first step water appliance protective systems and food grade PVC pipes. A flow metre Decast Metronic BKCM-15 in the system provided accurate registration of water volume for each sample, which varied from 2 to $5 \mathrm{~m}^{3}$ per sample. After every sampling period, collected material was rinsed from the filtration system by backward water flow within the system and filtered onto a stainless steel mesh filters ( $\varnothing 25 \mathrm{~mm}$, pore size $80 \mu \mathrm{m}$ ) using a filter holder attached directly to the sampling system to avoid contamination from the air. For this purpose, $25 \mathrm{~mm}$ filter holders were attached to outlets of the valve of the filtration system. Filters were sealed in glass jars pre-rinsed using pre-filtered $(0.45 \mu \mathrm{m})$ Milli-Q water. These jars were stored until the analysis in the onshore clean laboratory. In the laboratory, the samples were processed to remove organic matter using an optimised protocol with $10 \% \mathrm{KOH}^{61}$ in the same jars where the filters were stored. The processed samples were filtered onto $47 \mathrm{~mm}$ GF/A papers with $1.6 \mu \mathrm{m}$ pore size. The filter with material was immediately transferred to a petri dish and covered for drying and further analysis.

Contamination control. To mitigate sample contamination, a number of procedural steps were introduced. All equipment and glass jars were rinsed with prefiltered $(0.45 \mu \mathrm{m})$ Milli-Q water before use. Filters were checked under a microscope for contamination prior to use. The samples and used equipment were covered where possible with aluminium foil or glass to minimise periods of exposure. All consumables were taken directly from their packaging and checked for contamination if possible. As they were not checked for contamination, samples of these consumables were included in the spectra database. Personal protective equipment, $100 \%$ cotton lab coats and gloves were worn during the whole processing procedure. All procedures in the laboratory were conducted in a clean airflow cabinet (Labculture LA2-5A1-E).

To monitor the potential introduction of contamination field and procedural blanks were conducted. Specifically, during sampling field blanks were performed alongside the subsurface sampling procedure (1 field blank per 20 samples) using the same procedures as for subsurface sampling excluding seawater pumping when filters were in the filtration system.

In the laboratory procedural blanks ( 3 blanks per 20 samples, $10 \% \mathrm{KOH}$ in a glass jars) were run simultaneously with processing of subsurface samples. All field and procedural blanks were analysed for microplastics in the same way as other samples using a dissecting microscope Nikon SMZ745 after filtering onto GF/A paper.

Microplastics identification. All particles from surface and subsurface samples (as well as procedural and field blanks) were analysed using a combination of visual inspection and chemical identification of polymeric composition via spectroscopy methods. Particles collected with a $200-\mu \mathrm{m}$ neuston net were visually inspected in the 
vessel laboratory, and the following characteristics were described: morphology (fibres or fragments), size $(\mathrm{mm})$ and surface areas $\left(\mathrm{mm}^{2}\right)$. The obtained samples were photographed with a Nikon D750 camera and Tamron SP AF 28-75/2.8 XR LD lens. All particles were weighed (mg) in the onshore clean laboratory followed by identification of chemical composition of the obtained material using a Fourier Transform Infrared spectroscopy (FT-IR) analysis on PerkinElmer Spotlight 400 FTIR (Frontier ATR). Measurements were obtained at $4 \mathrm{~cm}^{-1}$ spectral resolution for the range 4000 to $600 \mathrm{~cm}^{-1}$. Library matching was performed in the Spectrum 10 software (v. 10.6.2). Each spectrum was compared to several different libraries available at NIVA: PerkinElmer ATR Polymers library, STJapan Polymers ATR library, BASEMAN library ${ }^{62}$, and several in-house libraries including reference polymers, different textile materials, and potential sources of laboratory contamination. All spectra were manually inspected to ensure that the library matches were acceptable.

Subsurface samples on GF/A filter papers were visually examined under a dissecting microscope Nikon SMZ745T fitted with an Infinity 1-3C camera and the associated Infinity Analyze software. Photographs of all potential microplastics were recorded, size $(\mathrm{mm})$ and surface area $\left(\mathrm{mm}^{2}\right)$ were measured using Image software, and their morphology (fibres or fragments) was described. Visual identification followed ${ }^{63}$ where fibres are distinguished from fragments based on the length to width composition. All selected particles from each sample were subjected to further chemical characterisation using $\mu \mathrm{FT}$-IR analysis on PerkinElmer Spotlight 400 FTIR (transmission micro-FTIR with DCC). The spectra were processed the same way as for the surface samples, details are given in ${ }^{63}$. The weight of subsurface microplastics was estimated on the base of the polymer density and volume of every particle, with an assumption that all the fibres are cylinders with visible diameter, and the fragments thickness was roughly estimated by comparison with the sizes of the fibres nearby.

Statistical analysis. Particle characteristics (morphology, size, weight and polymer type) and metadata on sampling conditions (coordinates, water temperature, water salinity, wind speed, vessel velocity, time from the start of the observations and volume of filtered water) were compiled in Microsoft Excel. All data were processed and visualised using python scientific and graphical packages (SciPy, Pandas, Matplotlib, Basemap, Q-GIS). The Pearson correlation matrix was calculated to estimate the possible relationships between the sampling conditions and the measured characteristics of microplastics in surface and subsurface layers (Supplementary Tables S1 and S2). A series of tests were conducted to identify statistically confident differences $(p<0.05)$ among characteristics of microplastics sampled within different water masses. The pairwise Student's $t$ test with Holm's procedure to control family-wise error rate was applied for numerical parameters (Supplementary Tables S3 and S7). These include parameters for surface samples: number and weight concentrations of microplastics; and for subsurface samples: abundance of fibres, fragments and total microplastics, mean size, weight concentration, weight of microplastics and surface area. Friedman test (Supplementary Tables S4 and S8) and post-hoc Conover test (Supplementary Tables S5 and S9) were used to compare the categorical samples (polymer type of microplastics) and the Fisher exact test (Supplementary Tables S6, S8 and S10) for binary features (the form of microplastics: fragment or fibre).

\section{Data availability}

The datasets generated during the current study are available at https://doi.org/10.5281/ zenodo.4321416.

Received: 18 May 2020; Accepted: 16 December 2020; Published online: 03 February 2021

\section{References}

1. Borrelle, S. B. et al. Opinion: Why we need an international agreement on marine plastic pollution. Proc. Natl Acad. Sci. USA 114, 9994-9997 (2017).

2. Haward, M. Plastic pollution of the world's seas and oceans as a contemporary challenge in ocean governance. Nat. Commun. 9, 1-3 (2018).

3. Ferraro, G. \& Failler, P. Governing plastic pollution in the oceans: Institutional challenges and areas for action. Environ. Sci. Policy 112, 453-460 (2020).

4. GESAMP. Guidelines for the monitoring and assessment of plastic litter and microplastics in 476 the ocean (eds. Kershaw P.J., Turra A. \& Galgani F.), (IMO/FAO/UNESCO477 IOC/UNIDO/WMO/IAEA/UN/UNEP/UNDP/ISA Joint Group of Experts on the Scientific478 Aspects of Marine Environmental Protection). Rep. Stud. GESAMP Vol. 99, p. 130 (2019).

5. Avio, C. G., Gorbi, S. \& Regoli, F. Plastics and microplastics in the oceans: from emerging pollutants to emerged threat. Marine Environ. Res. 128, 2-11 (2017).

6. Taylor, M. L., Gwinnett, C., Robinson, L. F. \& Woodall, L. C. Plastic microfibre ingestion by deep-sea organisms. Sci. Rep. 6, 33997 (2016)

7. La Beur, L. et al. Baseline assessment of marine litter and microplastic ingestion by cold-water coral reef benthos at the east mingulay marine protected area (sea of the hebrides, Western Scotland. Front. Mar. Sci. 6, 80 (2019).
8. Sfriso, A. A. et al. Microplastic accumulation in benthic invertebrates in Terra Nova Bay (Ross Sea, Antarctica). Environ. Int. 137, 105587 (2020)

9. Obbard, R. W. et al. Global warming releases microplastic legacy frozen in Arctic Sea ice. Earth's Future 2, 315-320 (2014).

10. Lusher, A. L., Tirelli, V., O'Connor, I. \& Officer, R. Microplastics in Arctic polar waters: the first reported values of particles in surface and sub-surface samples. Sci. Rep. 5, 14947 (2015).

11. Bergmann, M. et al. High quantities of microplastic in Arctic deep-sea sediments from the HAUSGARTEN observatory. Environ. Sci. Technol. 51, 11000-11010 (2017)

12. Cózar, A. et al. The Arctic Ocean as a dead end for floating plastics in the North Atlantic branch of the Thermohaline Circulation. Sci. Adv. 3, e1600582 (2017).

13. Barrows, A. P. W., Cathey, S. E. \& Petersen, C. W. Marine environment microfiber contamination: global patterns and the diversity of microparticle origins. Environ. Pollut. 237, 275-284 (2018).

14. Peeken, I. et al. Arctic sea ice is an important temporal sink and means of transport for microplastic. Nat. Commun. 9, 1-12 (2018).

15. Morgana, S. et al. Microplastics in the Arctic: a case study with sub-surface water and fish samples off Northeast Greenland. Environ. Pollut. 242, 1078-1086 (2018).

16. Kanhai, L. D. K. et al. Microplastics in sub-surface waters of the Arctic Central Basin. Marine Pollut. Bull. 130, 8-18 (2018).

17. Fang, C. et al. Microplastic contamination in benthic organisms from the Arctic and sub-Arctic regions. Chemosphere 209, 298-306 (2018).

18. Bergmann, M. et al. White and wonderful? Microplastics prevail in snow from the Alps to the Arctic. Sci. Adv. 5, eaax1157 (2019).

19. $\mathrm{Mu}$, J. et al. Microplastics abundance and characteristics in surface waters from the Northwest Pacific, the Bering Sea, and the Chukchi Sea. Marine Pollut. Bull. 143, 58-65 (2019).

20. Kanhai, L. D. K. et al. Deep sea sediments of the Arctic Central Basin: a potential sink for microplastics. Deep Sea Res. Part I Oceanogr. Res. Pap. 145, 137-142 (2019).

21. Halsband, C. \& Herzke, D. Plastic litter in the European Arctic: what do we know? Emerg. Contam. 5, 308-318 (2019).

22. Kanhai, L. D. K., Gardfeldt, K., Krumpen, T., Thompson, R. C. \& O’Connor, I. Microplastics in sea ice and seawater beneath ice floes from the Arctic ocean. Sci. Rep. 10, 1-11 (2020).

23. Tekman, M. B. et al. Tying up loose ends of microplastic pollution in the arctic: distribution from the sea surface through the water column to deep-sea sediments at the HAUSGARTEN observatory. Environ. Sci. Technol. 54, 4079-4090 (2020).

24. Tirelli, V., Suaria, G. \& Lusher, A. L. Microplastics in polar samples. Handbook of Microplastics in the Environment. pp. 1-42 (Springer, Cham, 2020).

25. PAME. Desktop Study on Marine Litter including Microplastics in the Arctic (2019).

26. Fichot, C. G. et al. Pan-Arctic distributions of continental runoff in the Arctic Ocean. Sci. Rep. 3, 1053 (2013).

27. Lebreton, L. C. et al. River plastic emissions to the world's oceans. Nat. Commun. 8, 15611 (2017)

28. Hurley, R., Woodward, J. \& Rothwell, J. J. Microplastic contamination of river beds significantly reduced by catchment-wide flooding. Nat. Geosci. 11, 251-257 (2018)

29. Gordeev, V. V., Martin, J. M., Sidorov, I. S. \& Sidorova, M. V. A reassessment of the Eurasian river input of water, sediment, major elements, and nutrients to the Arctic Ocean. Am. J. Sci. 296, 664-691 (1996).

30. Carmack, E. C. The Arctic Ocean's freshwater budget: sources, storage and export. In The freshwater budget of the Arctic Ocean. p. 91-126 (Springer, Dordrecht, 2000).

31. Guay, C. K. et al. Wind-driven transport pathways for Eurasian Arctic river discharge. J. Geophys. Res. Oceans 106, 11469-11480 (2001).

32. Rabe, B. et al. An assessment of Arctic Ocean freshwater content changes from the 1990s to the 2006-2008 period. Deep Sea Res. Part I Oceanogr. Res. Pap. 58, 173-185 (2011).

33. Timmermans, M. L., \& Marshall, J. Understanding Arctic ocean circulation: a review of ocean dynamics in a changing climate. J. Geophys. Res. Oceans $\mathbf{1 2 5}$, e2018JC014378 (2020).

34. Rudels, B., Jones, E. P., Schauer, U. \& Eriksson, P. Atlantic sources of the Arctic Ocean surface and halocline waters. Polar Res. 23, 181-208 (2004).

35. Årthun, M., Ingvaldsen, R. B., Smedsrud, L. H. \& Schrum, C. Dense water formation and circulation in the Barents Sea. Deep Sea Res. Part I Oceanogr. Res. Pap. 58, 801-817 (2011).

36. Aagaard, K. On the deep circulation of the Arctic Ocean. Deep-Sea Res. 28, 251-268 (1981) 
37. Polyakov, I. V. et al. Fate of early-2000s Arctic warm water pulse. Bull. Am. Meteor. Soc. 92, 561-566 (2011).

38. Polyakov, I. V., Pnyushkov, A. V. \& Timokhov, L. A. Warming of the Intermediate Atlantic Water of the Arctic Ocean in the 2000s. J. Clim. 25, 8362-8370 (2012).

39. Osadchiev, A. A. et al. Structure of the buoyant plume formed by $\mathrm{Ob}$ and Yenisei river discharge in the southern part of the Kara Sea during summer and autumn. J. Geophys. Res. Oceans 122, 5916-5935 (2017).

40. Osadchiev, A. A. et al. Bottom sediments reveal inter-annual variability of interaction between the $\mathrm{Ob}$ and Yenisei plumes in the Kara Sea. Sci. Rep. 9, 1-11 (2019).

41. Semiletov, I. P. et al. Carbon transport by the Lena River from its headwaters to the Arctic Ocean, with emphasis on fluvial input of terrestrial particulate organic carbon vs. carbon transport by coastal erosion. Biogeosciences $\mathbf{8}$, 2407-2426 (2011).

42. Fofonova, V. et al. Impact of wind and tides on the Lena River freshwater plume dynamics in the summer season. Ocean Dyn. 65, 951-968 (2015).

43. Rudels, B. The foromation of Polar Surface Water, the ice export and the exchanges through the Fram Strait. Progr. Oceanogr. 22, 205-248 (1989).

44. Rudels, B. Arctic Ocean circulation and variability-advection and external forcing encounter constraints and local processes. Ocean Sci. 8, 261-286 (2012).

45. Schauer, U., Loeng, H., Rudels, B., Ozhigin, V. K. \& Dieck, W. Atlantic water flow through the Barents and Kara Seas. Deep Sea Res. Part I Oceanogr. Res. Pap. 49, 2281-2298 (2002).

46. Aksenov, Y., Bacon, S., Coward, A. C. \& Nurser, A. G. The North Atlantic inflow to the Arctic Ocean: High-resolution model study. J. Mar. Syst. 79, $1-22(2010)$.

47. Kwok, R., Spreen, G. \& Pang, S. Arctic sea ice circulation and drift speed: decadal trends and ocean currents. J. Geophys. Res. Oceans 118, 2408-2425 (2013).

48. Dmitrenko, I., Kirillov, S., Eicken, H. \& Markova, N. Wind-driven summer surface hydrography of the eastern Siberian shelf. Geophys. Res. Lett. 32, 1-5 (2005).

49. Panteleev, G., Proshutinsky, A., Kulakov, M., Nechaev, D. A. \& Maslowski, W. Investigation of the summer Kara Sea circulation employing a variational data assimilation technique. J. Geophys. Res. Oceans 112, 1-21 (2007).

50. Semiletov, I. P. et al. The Dispersion of Siberian River Flows into Coastal Waters: Meteorological, Hydrological and Hydrochemical Aspects. The Freshwater Budget of the Arctic Ocean, NATO Meeting/NATO ASI Series (ed. E. L. Lewis) p. 323-367 (Kluwer Academic Publishers, Dordrecht, 2000).

51. Yang, X. Y., Yuan, X. \& Ting, M. Dynamical link between the Barents-Kara sea ice and the Arctic Oscillation. J. Clim. 29, 5103-5122 (2016).

52. Wagner, M. et al. Microplastics in freshwater ecosystems: what we know and what we need to know. Environ. Sci. Eur. 26, 1-9 (2014).

53. Eerkes-Medrano, D., Thompson, R. C. \& Aldridge, D. C. Microplastics in freshwater systems: a review of the emerging threats, identification of knowledge gaps and prioritisation of research needs. Water Res. 75, 63-82 (2015).

54. Horton, A. A., Walton, A., Spurgeon, D. J., Lahive, E. \& Svendsen, C Microplastics in freshwater and terrestrial environments: evaluating the current understanding to identify the knowledge gaps and future research priorities. Sci. Total Environ. 586, 127-141 (2017).

55. Van der Wal, M. et al. Identification and assessment of riverine input of (marine) litter. Final Report for the European Commission DG Environment under Framework Contract No ENV.D.2/FRA/2012/0025 (2015).

56. Van Sebille, E., England, M. H. \& Froyland, G. Origin, dynamics and evolution of ocean garbage patches from observed surface drifters. Environ Res. Lett. 7, 044040 (2012)

57. Rivers, M. L., Gwinnett, C. \& Woodall, L. C. Quantification is more than counting: Actions required to accurately quantify and report isolated marine microplastics. Mar. Pollut. Bull. 139, 100-104 (2019).

58. Michida, Y. et al. Guidelines for Harmonizing Ocean Surface Microplastic Monitoring Methods (2019).

59. Bruge, A. et al. Monitoring litter inputs from the Adour River (Southwest France) to the marine environment. J. Mar. Sci. Eng. 6, 24 (2018).

60. Kosmach, D. A. et al. Methane in the surface waters of Northern Eurasian marginal seas. Dokl. Chem. Pleiades Publ. 465, 281-285 (2015).

61. Bråte, I. L. N. et al. Mytilus spp. as sentinels for monitoring microplastic pollution in Norwegian coastal waters: a qualitative and quantitative study. Environ. Pollut. 243, 383-393 (2018).
62. Primpke, S. et al. Reference database design for the automated analysis of microplastic samples based on Fourier transform infrared (FTIR) spectroscopy. Anal. Bioanal. Chem. 410.21, 5131-5141 (2018).

63. Lusher, A., Bråte, I. L. N., Munno, K., Hurley, R. \& Welden, N. EXPRESS: is it or isn't it: the importance of visual classification in microplastic characterization. Appl. Spectrosc. p. 74, 0003702820930733 (2020).

64. Lusher, A. L., Burke, A., O'Connor, I. \& Officer, R. Microplastic pollution in the Northeast Atlantic Ocean: validated and opportunistic sampling. Mar. Pollut. Bull. 88, 325-333 (2014).

65. Thompson, R. C. et al. Lost at sea: where is all the plastic? Science 304, 838-838 (2004).

66. Law, K. L. et al. Plastic accumulation in the North Atlantic subtropical gyre. Science 329, 1185-1188 (2010).

67. do Sul, J. A. I., Costa, M. F., Barletta, M. \& Cysneiros, F. J. A. Pelagic microplastics around an archipelago of the Equatorial Atlantic. Mar. Pollut. Bull. 75, 305-309 (2013).

\section{Acknowledgements}

This work was partly funded by the Norwegian Ministry of Climate and Environment project RUS-19/0001 "Establish regional capacity to measure and model the distribution and input of microplastics to the Barents Sea from rivers and currents (ESCIMO)"; the Ministry of Science and Higher Education of Russia, theme 0149-2019-0003; the Russian Government (\#14, Z50.31.0012/03.19.2014); the Ministry of Science and Higher Education of the Russian Federation (grant ID: 075-15-2020-928 and 0211-2021-0010), the Russian Foundation for Basic Research, research projects 19-55-80004, 20-35-70039 and 20-35-90056; the Russian Scientific Foundation grant 18-77-10004 and Tomsk Polytechnic University Competitiveness Enhancement Program VIU-OG-215/220. Authors are grateful to Oleg Dudarev, Vladimir Rogozhin and Denis Kosmach for assistance during samples collecting, the captain and crew of R/V Akademik Mstislav Keldysh for facilitating the survey and to Yuliya Ermilova for technical assistance with GIS mapping

\section{Author contributions}

E.Y., A.G., B.B., I.S., S.P. and A.L. designed and coordinated the study; E.Y., A.G., A.O. A.B., E.V., G.K., I.R., D.C. and I.S. conducted field work and collected the samples; S.P. and A.B. processed the samples and conducted data analyses; E.Y., A.G., A.O., S.P., A.L., A.B. and B.B. wrote the article. All authors reviewed and commented to the final version.

\section{Competing interests}

The authors declare no competing interests.

\section{Additional information}

Supplementary information The online version contains supplementary material available at https://doi.org/10.1038/s43247-021-00091-0.

Correspondence and requests for materials should be addressed to E.Y. or A.G.

Peer review information Primary handling editor: Joseph Aslin

Reprints and permission information is available at http://www.nature.com/reprints

Publisher's note Springer Nature remains neutral with regard to jurisdictional claims in published maps and institutional affiliations.

Open Access This article is licensed under a Creative Commons Attribution 4.0 International License, which permits use, sharing, adaptation, distribution and reproduction in any medium or format, as long as you give appropriate credit to the original author(s) and the source, provide a link to the Creative Commons license, and indicate if changes were made. The images or other third party material in this article are included in the article's Creative Commons license, unless indicated otherwise in a credit line to the material. If material is not included in the article's Creative Commons license and your intended use is not permitted by statutory regulation or exceeds the permitted use, you will need to obtain permission directly from the copyright holder. To view a copy of this license, visit http://creativecommons.org/ licenses/by/4.0/.

(C) The Author(s) 2021, corrected publication 2022 